\title{
Modeling, Simulation, and Developments of Metallurgical Processes
}

\author{
ZHIWEI PENG, ${ }^{1,2,5}$ DEAN GREGUREK, ${ }^{3,6}$ and PHILLIP J. MACKEY ${ }^{4,7}$ \\ 1.-School of Minerals Processing and Bioengineering, Central South University, Changsha, \\ Hunan 410083, China. 2.-Department of Materials Science and Engineering, Michigan Techno- \\ logical University, Houghton, MI 49931, USA. 3.-RHI AG, Technology Center Leoben, Magne- \\ sitstrasse 2, Leoben 8700, Austria. 4.-P.J. Mackey Technology Inc., Montreal, QC H9J 1P7, \\ Canada. 5.—e-mail: zwpeng@csu.edu.cn. 6.—e-mail: Dean.Gregurek@rhi-ag.com. 7.—e-mail: \\ pjmackey@hotmail.com
}

The processes in extractive metallurgy are typically carried out in a harsh environment, coupled with sometimes complex operations, which can make direct measurements needed for process optimization quite difficult. Noteworthy is that process simulations based on versatile physical, mathematical, and data-based models have proven to be effective investigative tools to improve metallurgical processes, leading to lower production costs, enhanced product quality, and in many cases, improved environmental sustainability.

This special topic presents eight articles showing how recent advances in the modeling, simulation, and development of metallurgical processes can lead to improved technologies. The first article is concerned with the properties of slags (e.g., electrical conductivity), which are important for smooth technical operation and product quality during metal purification. In this article titled, "Estimation Model for Electrical Conductivity of Molten $\mathrm{CaF}_{2}$ $\mathrm{Al}_{2} \mathrm{O}_{3}-\mathrm{CaO}$ Slags Based on Optical Basicity," Burak Birol et al. propose a new model for predicting electrical conductivity of $\mathrm{CaF}_{2}$ containing electroslag remelting (ESR) slags. They present a mathematical equation for determining the relationship between the optical basicity and the measured electrical conductivity between $1450^{\circ} \mathrm{C}$ and $1600^{\circ} \mathrm{C}$. The work offers a valuable guide for the control of these metal purification operations.

In the next article titled, "Prediction of Multipreform Shapes in Warm Forming with Experimental Verification," Ting Fai Kong and Luen Chow Chan propose a computer-aided simulation

Zhiwei Peng, Dean Gregurek, and Phillip Mackey are the guest editors for the Pyrometallurgy Committee of the TMS Extraction \& Processing Division, and coordinators of the topic Modeling, Simulation, and Development of Metallurgical Processes: Part II in this issue. approach for predicting the multipreform shapes of warm-forming intricate components. With this method, the material utilization rate was improved by $50 \%$, and at the same time, the production cost and time for full material utilization were reduced by $40 \%$ and $20 \%$, respectively. The computer simulation methodology provided demonstrates a remarkably cost-saving and effective approach for improving the warm-forming process.

Magnesium-based alloys have many benefits over other metal alloys but suffer difficulties in achieving good formability, which can be improved in a hydroforming process. In the third article titled, "Finite-Element Damage Analysis for Failure Prediction of Warm Hydroforming Tubular Magnesium Alloy Sheets," Luen Chow Chan reports on the failure prediction of $\mathrm{Mg}$-based alloy during tube hydroforming process at high temperatures using the Marciniak and Kuczynski model. It was concluded that the model is reliable in predicting the failure of the alloy tube during the process, but the author also noted that the discrepancies between the numerical and experimental results were caused mainly by setting approximate simulation parameters.

The COREX process is an alternative ironmaking process designed for satisfying increasingly severe resource and environmental demands. Due to the difficulty in direct measurement of the internal conditions of the COREX process, Mingyin Kou et al. developed a mathematical quarter sectional model for describing the gas and burden distributions inside the COREX shaft furnace in the fourth article titled, "The Effect of Operational Parameters on the Characteristics of Gas-Solid Flow Inside COREX Shaft Furnace." It was found that the reducing gas flow should be adjusted step by step, and the volume fraction of gas phase needs to be 
increased to obtain a higher metallization rate. The separate discharge of ore and coke also contributes to a higher metallization rate.

In the fifth article, which is titled, "Upgradation of Metals via Direct Reduction from Polymetallic Titaniferous Magnetite Ore," Saikat Samanta et al. compare the isothermal reduction behavior of a titaniferous magnetite lump ore, a pretreated (preheating before quenching) ore, and ore-coke composite briquettes. Due to distinct reduction behaviors of these materials, iron, vanadium and titanium have been effectively separated via direct reduction followed by magnetic separation. This type of interesting and flexible metallurgical process seems particularly suitable for the utilization of polymetallic resources for greater sustainability.

As a primary source of zinc, zinc sulfide concentrate usually contains a small amount of silver. Recovering silver along with zinc is important for improving the process economics. In the article titled, "Separation of Silver from a Zinc Sulfide Concentrate by a Co-Smelting Process," Jian-Guang Yang et al. propose a new approach that effectively separates silver from a zinc sulfide concentrate through co-smelting with lead oxide dust. This approach not only contributed to a high silver separation rate $(>97 \%)$ but also produced a high-grade zinc sulfide concentrate $(>43 \%)$ with simultaneous removal of associated impurities including arsenic, cadmium, and halide elements that were present in the material. The work provides a promising option for comprehensive recovery of zinc and silver from various metal resources.

Building on an earlier TMS proceedings paper, Eli Ringdalen, in the seventh article titled, "Changes in Quartz during Heating and the Effect on Si-Production, Initial Studies," reports on the effect of quartz type on rate of quartz-cristobalite transformation and formation of amorphous silica during silicon production. It was shown that the quartz type considerably affects the transformation rate and amorphous silica formation. The test results offer a valuable guide for improving performance of furnaces for silicon production by selecting proper type of quartz as a silicon source.

The last article in this series by Ailiang Chen et al., "Recovery of Silver and Gold from Copper Anode Slimes" provides a status overview of the extraction processes for recovering silver and gold from conventional copper anode slimes. The pyrometallurgical processes, hydrometallurgical processes, and processes involving a combination of pyrometallurgical and hydrometallurgical technologies were evaluated based in part on a review of the form and characteristics of silver and gold in copper anode slimes. It was pointed out that the combined processes offer a promising approach for efficient extraction of silver and gold from the slimes with high extraction yields achieved in different steps of these processes by taking advantages of both pyrometallurgical and hydrometallurgical technologies.

The selected articles highlighted in this topic represent a sampling of recent and what the authors consider as exciting progress in modeling, simulation, and experimental efforts covering a diverse range of metallurgical fields. The stimulating findings and innovations presented are considered worthwhile in promoting the development of metallurgical processes from both theoretical and practical perspectives.

The following papers now being published under the topic of "Modeling, Simulation, and Developments of Metallurgical Processes" provide excellent details and research on the subject. To download any of the papers, follow the URL http://link.springer. com/journal/11837/67/2/page/1 to the table of contents page for the February 2015 issue (vol. 66, no. 2).

- "Estimation Model for Electrical Conductivity of Molten $\mathrm{CaF}_{2}-\mathrm{Al}_{2} \mathrm{O}_{3}-\mathrm{CaO}$ Slags Based on Optical Basicity," by Burak Birol, Gokhan Polat, and Muhlis Nezihi Saridede

- "Prediction of Multipreform Shapes in Warm Forming with Experimental Verification," by Ting Fai Kong and Luen Chow Chan

- "Finite-Element Damage Analysis for Failure Prediction of Warm Hydroforming Tubular Magnesium Alloy Sheets," by Luen Chow Chan

- "The Effect of Operational Parameters on the Characteristics of Gas-Solid Flow inside COREX Shaft Furnace," by Mingyin Kou, Shengli Wu, Kaiping Du, Wei Shen, Xiaodong Ma, Mao Chen, and Baojun Zhao

- "Upgradation of Metals via Direct Reduction from Polymetallic Titaniferous Magnetite Ore," by Saikat Samanta, Siddhartha Mukherjee, and Rajib Dey

- "Separation of Silver from a Zinc Sulfide Concentrate by a Co-Smelting Process," by Jian-Guang Yang, Xu-Liang Zhang, and Jian-Ying Yang

- "Changes in Quartz During Heating and the Effect on Si Production, Initial Studies," by Eli Ringdalen

- "Recovery of Silver and Gold from Copper Anode Slimes," by Ailiang Chen, Zhiwei Peng, JiannYang Hwang, Yutian Ma. Xuheng Liu, and Xingyu Chen 